\title{
Same time, across time: simultaneity clauses from Late Modern to Present-Day English*
}

\author{
CRISTIANO BROCCIAS \\ Università di Genova \\ and \\ NICHOLAS SMITH \\ University of Salford \\ (Received 15 February 2009; revised 27 January 2010)
}

\begin{abstract}
In this article we offer a diachronic analysis of simultaneity subordinator as against the background of simultaneity subordinators while, whilst, when from 1650 to the end of the twentieth century. The present survey makes use of data extracted from the British English component of ARCHER (version 3.1), focusing in particular on fiction, the register par excellence for the use of simultaneity subordinators. We analyse our data according to a selection of parameters (ordering, verb type, duration, tense and aspect, subject identity, simultaneity type) and show that, against a background of relative stability, the major change is a dramatic increase in the frequency of simultaneity as-clauses from the first half of the nineteenth century onwards. Adapting the historical work on stylistic change by Biber and Finegan $(1989,1997)$, as well as theoretical and experimental accounts of the semantics of English simultaneity markers, we highlight an interesting parallelism between the spread of as-clauses in oral narrative from childhood to adulthood and the spread of as-clauses in modern fiction. In either case, the spread of as may be symptomatic of an evolution in narrative techniques, particularly in respect of the means by which complex events are typically represented.
\end{abstract}

\section{Introduction}

This article deals with the historical development of simultaneity clauses, in particular as-clauses, from the so-called Late Modern English (LModE) period up to, and including, Present-Day English (PDE), roughly from c.1650 onwards. ${ }^{1}$ The term 'simultaneity' is used here to refer to partial or complete overlap between two situations (see Quirk et al. 1985: 1083-4; Schmiedtová 2004: 9 inter alia). Such a temporal

* Earlier versions of this article were presented at the Third Late Modern English Conference at the University of Leiden in 2007, the Fifteenth International Conference on English Historical Linguistics at the University of Munich in 2008 and at research seminars at the universities of Freiburg, Salford and Huddersfield in 2008. We are very grateful to the audiences for their comments. We also benefitted greatly from the comments of the two anonymous reviewers. We would also like to thank all those who replied to our query on the evolution of fiction which we posted on the Linguist List in September 2008 (no. 19.2739) as well as Sandro Jung, Anneli Meurman-Solin, Teresa Fanego and Geoffrey Leech, who provided us with very useful feedback on various occasions. Finally, special thanks go to Douglas Biber for clarifying certain aspects of his and Edward Finegan's work and David Denison for his help and encouragement. Needless to say, all remaining errors are our own.

1 The year 1700 is also often used as the (admittedly arbitrary) starting point of LModE; see Beal (2004). Here we will be using the year 1650 as a reference point since the corpus we used, ARCHER 3.1 (see section 2), starts from that year. 
relation can be expressed in various ways in English. At a minimum, a simultaneity interpretation can follow via pragmatic inference from mere juxtaposition of two clauses, as in (1a). Alternatively, a simultaneity link between situations can be made explicit by the use of an adverbial such as simultaneously or a prepositional phrase, such as the fixed (and anaphoric) expression in the meantime or a phrase headed by during, as in (1b-d). Of course, the options presented in (1) are by no means exhaustive.

(1) (a) I was washing up. Sally was reading.

(b) Simultaneously, he topped the JA and New York charts. (British National Corpus (BNC): CAD 1485)

(c) In the meantime, we have to step up our efforts to find this damn ship. (BNC: CEC 2826)

(d) During my earlier periods of unemployment I had always, on a point of pride, provided for myself out of my savings. (BNC: A0F 1005)

One further possibility involves the use of the subordinators as, while, whilst and when, as in (2).

(2) (a) An armed robber was mugged of his loot as he made his getaway. (BNC: CBF 1497; also quoted in Biber et al. 1999: 846).

(b) She said that the pain was a little better after the pethidine she had been given and she was able to rest quietly while she waited to be taken to theatre. (BNC: EV5 1161; also quoted in Biber et al. 1999: 849)

(c) Whilst he was shaving realization began to dawn that something was amiss (BNC: B20 1978).

(d) When he was in the air force he once spent the weekend cycling uphill for 11 hours against the wind... (BNC: CME 465)

Additionally, bare participles and participles as complements of either prepositions (e.g. upon) or subordinators (e.g. whilst) can also be recruited to signal simultaneity explicitly, as in (3). ${ }^{2}$

(3) (a) Walking home from his job one payday, he was set upon by two young men ... (BNC: C9W 565)

(b) Upon entering the grand hall where Tamar sat, he gave her a quick teasing smile. (BNC: C98 144)

(c) First aid for a bleeding nose is to pinch the nostrils closed whilst tilting the head back. (BNC: A0M 1375)

The present article will focus on cases like (2), where the subordinators as/while/whilst/when are employed. In their simultaneity function these subordinators tend to be treated as roughly equivalent variants in descriptive grammars and dictionaries (see e.g. Quirk et al. 1985: 1083-4 and e.g. entry III, 16.a for $a s$, adv. (conj., and rel. pron.), in the Oxford English Dictionary at www.oed.com). However, important differences between them have been observed (see e.g. Broccias 2006a, 2006b, 2008;

\footnotetext{
${ }^{2}$ We are ignoring the elliptical type where the verb be is omitted and the subordinator is immediately followed by a PP, as in while on duty, when at work, etc. Note incidentally that this pattern is not possible with as (*as at work) because of the general ban on stative be with temporal as (see the next paragraph in the text).
} 
Morris 1996; Övergaard 1987; Silva 1991). As-clauses, unlike when/while/whilst clauses, do not seem to combine with stative be (cf. She called *as/while he was here $)^{3}$ and typically occur with verbs designating a change of position or state; see also (2a) vs (2b-d). Broccias (2006b), for example, finds that change verbs account for about 72 per cent of simultaneity as-clauses in the fiction section of the BNC. For this reason, he regards as-clauses as typically activating a 'path-schema': the as-clause event is construed as an event with a high potential for change. Silva (1991: 649), more generally, observes that ' $[W]$ hen [is] the least specific as to the exact temporal relationship among events and the least constrained as to the nature of the predicates it can connect, and as [is] the most specific and constrained, leaving while to occupy the middle ground'; see also Broccias (2006a).

It therefore seems worthwhile to investigate the extent to which use of the subordinators as/while/whilst/when has altered over time, and if it has, how we can account for the changes. Such questions, to the best of our knowledge, have never been addressed before ${ }^{4}$ - indeed simultaneity clauses, in particular as-clauses, have been somewhat neglected as a research topic. This article seeks to fill this gap by offering the first ever diachronic analysis of simultaneity subordinators in the Modern English period from the latter half of the seventeenth century to the end of the twentieth century, with special attention to the 'Cinderella' of the simultaneity subordinators, i.e. as. ${ }^{5}$ For this we take a corpus-based approach focusing on British English fiction, where examples are most numerous. Such a study is of course important not only descriptively but also theoretically, since any observable changes need to be accounted for. Indeed, our corpus evidence shows that the traditionally most neglected of the four simultaneity subordinators, $a s$, is in fact the most interesting diachronically. Against a background of relative stability, we observe a fivefold increase in the number of temporal as-clauses from the beginning of the nineteenth century in fiction. We assess this change in relation to Biber and Finegan's pioneering work on stylistic change, and although we show that the increase in as-clauses may converge with Biber and Finegan's idea that fiction has become more 'situated' over the last couple of centuries, we argue that this trend cannot necessarily be taken as evidence of an increasing degree of orality in fiction, as Biber and Finegan (1989: 504) seem to argue. Rather, using psycholinguistic evidence from Silva (1991), we contend that the spread of as-clauses reflects a more 'sophisticated' approach to narration since a similar trend is also observed as children mature into adulthood. Moreover, we observe that this conclusion seems compatible with Biber's (2008) most recent work on emergent grammar in different genres or registers.

${ }^{3}$ As he was here can of course be used with a causal interpretation. Notice also that posture verbs, which could be classified as stative, are possible (cf. She called as he lay there); see Broccias (2006a) for detailed discussion.

${ }^{4}$ In fact, temporal adverbials have been studied diachronically by Pasicki (1983, 1987). However, his main concern was a 'structural' one, i.e. to provide structural descriptions of the various patterns in a generative grammar format. He does not discuss what factors may have influenced the choice of a particular subordinator over the others. Further, his investigation does not extend to the Late Modern English period but ends with the Middle English period.

${ }^{5}$ Note, however, that there is a precedent for corpus-based investigation of the non-simultaneity uses of the subordinator while, across a broadly similar historical period; see González-Cruz (2007). 


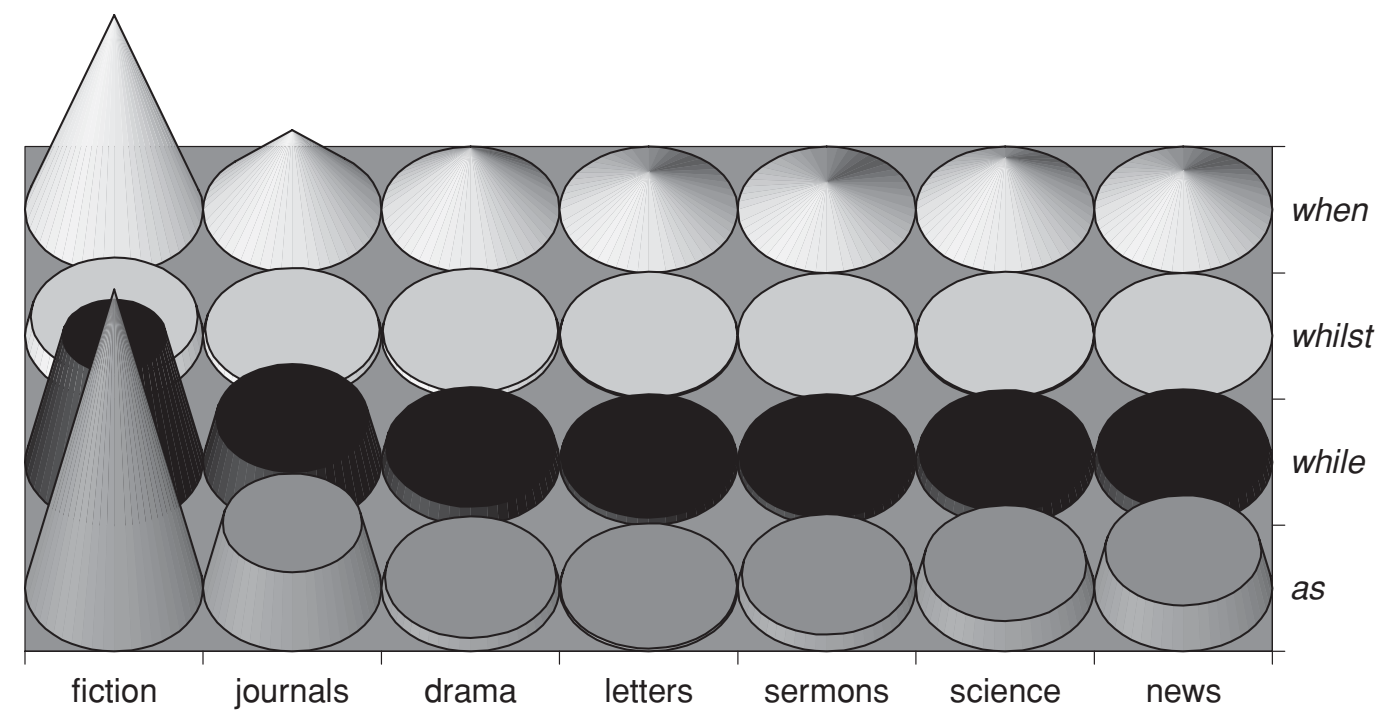

Figure 1. Subordinators across all registers

The article is structured as follows. It first describes how the corpus instances of simultaneity were extracted, selected and annotated (section 2). Section 3 details our findings for the subordinator as against while, whilst and when. Finally, section 4 attempts to offer an explanation for the main finding of our article (i.e. the growth of simultaneity $a s$-clauses) and points to topics for future research.

2 Data extraction, selection and annotation

Our investigation was carried out using the British section of the 1.7 million word ARCHER corpus (A Representative Corpus of Historical English Registers, see Biber et al. 1994), version 3.1. We used the British English data because previous corpusbased studies (e.g. Broccias 2006b, 2008) concentrated on this variety, and because of the greater size and date coverage of the British English subcorpus. This material is divided chronologically into seven periods and includes eight registers; see figure 1 below and table 2 in section 3 for details.

In order to facilitate data extraction, i.e. to retrieve corpus examples of simultaneity introduced by the subordinators as/while/whilst/when, we first tagged ARCHER for parts-of-speech using the CLAWS (Garside \& Smith 1997) and Template Tagger (Smith 1997) software. Next, we extracted potential candidate cases of simultaneity clause using CQP (see Christ 1994). The core elements of the query were (a) the relevant subordinator (as, while, whilst or when), followed by (b) up to eleven optional words (excluding certain categories such as hard punctuation), followed by (c) a finite verb.

Since some of the texts included in ARCHER contain non-modernized variant spellings, while others have been modernized, our queries in CQP allowed for different spellings of the subordinators and verb forms. (For example, as well as while, we 
searched for vvhile, whileas, whiles, whlie, whyle, wyle; this returned just two uses of whiles, both of them nouns.) Although the subordinators themselves turned out to be nearly always in their present-day orthography, this was not the case with other word classes, notably past tense verbs and past participles ending in -'d, such as call'd. We are aware that some valid cases of simultaneity clause in the earliest ARCHER texts will have been missed, as a result of mistagging of either the finite verb at the end of the clause, or other material within the purported subordinate clause, especially in the context of spelling variants. Even so, manual inspections of the retrieved data suggest that the accuracy ('recall') of the query is acceptably high, and that the method used is much more efficient than searching for simultaneity constructions on the basis of their form alone.

From this initial data extraction, we identified cases fulfilling a temporal - as opposed to, for example, causal, comparative or concessive - function (see further, section 3.1.1). We decided to restrict our research to past-time contexts because instances of present and future simultaneity use were not nearly as frequent (amounting to fewer than onefifth of all cases in ARCHER), and certainly insufficient to support a detailed analysis. For instance, across all registers, 93 examples of as-present (i.e. simultaneity as clauses in the present tense) were found as opposed to 376 instances of $a$-past (i.e. simultaneity as clauses in the past tense). In the case of fiction, which is arguably the most important register for the study of simultaneity clauses (see below), the difference between aspresent clauses and as-past clauses is even more dramatic, the former amounting to 21 and the latter to 237 instances over the whole period 1650-1990. We also opted to disregard non-finite instances of the type shown in (3c) above because of the paucity of such examples (they amounted to less than ten per subordinator across all periods in fiction, for example).

Figure 1 shows the distribution of the simultaneity markers across all registers.

Perhaps unsurprisingly, figure 1 shows that most simultaneity examples occur in narrative registers, and especially in fiction; this is presumably because a central concern in fiction texts (at least for works in the realism tradition, which are in the majority in the Modern period) is the establishing and depicting of temporal relations between events and situations within an overall plot or storyline. The privileged role of fiction explains why our article discusses the behaviour of the various subordinators in this register in particular.

After data extraction and selection, we annotated relevant examples such as (4) below by using the parameters shown in table 1 . Previous studies have identified these parameters as being particularly important in differentiating simultaneity constructions in PDE; see e.g. Broccias (2006a, 2006b and 2008) and Silva (1991).

(4) As my Sister and I were sitting one day in a Grotto at the End of a Parterre, we saw the Marquis de Stainville and another Gentleman coming towards us. (ARCHER 1744fldg.(3b) ${ }^{6}$

${ }^{6}$ Henceforth, unless stated otherwise, all corpus examples come from ARCHER 3.1. The code identifying each ARCHER example gives first the year and then the text file in which the example occurs. In (4), the ' $\mathrm{f}$ ' after 
Table 1. An example of simultaneity as-clause coding

\begin{tabular}{|c|c|c|}
\hline Parameter & Simul clause & Main clause \\
\hline Clause order & $1 \mathrm{st}$ & 2nd \\
\hline Verb type & be: posture & perception \\
\hline Punctual? & no & yes \\
\hline Tense $\&$ aspect & past prog & past non-prog \\
\hline Identical subjects? & & \\
\hline Prototypical simultaneity? & & \\
\hline
\end{tabular}

Most of the labels for the various parameters should be self-explanatory. Clause order refers to the relative order of the simul (i.e. simultaneity) clause and the main clause. ${ }^{7}$ In (4), the as-clause precedes the main clause. Both verbs in the main clause and in the temporal clause were classified using a system inspired by Halliday's classification of processes (see Halliday 2004). ${ }^{8}$ Among the classes used are 'material', which we subdivided into 'change of place/of state' predicates (e.g. pass, grow) and predicates which are not of the 'change' type (e.g. rub); 'verbal', which has to do with verbs of saying; 'attention', which involves verbs of perception (either intentional or not) such as see in (4); 'behavioural', which groups verbs describing human behaviour (e.g. sigh, smile); 'mental', which refers to cognitive processes; 'be', which not only includes the verb be but also stative verbs of posture (such as sit in (4)), and a handful of minor types. (We have refrained from offering a detailed breakdown of all the classes because, for example, the percentages for non-change verbs in $a s$-clauses are relatively low; see also Broccias 2006a.) Punctuality is meant to specify whether the main clause or the temporal clause (or both) depicts events of relatively short or relatively long duration. Of course, the coding of this dimension is somewhat subjective and our results here should be regarded as more provisional than for the other categories analysed. In the example at hand, most readers would probably agree that the main clause event depicts a relatively short/punctual situation while the temporal clause depicts a non-punctual situation.

All instances were also coded for tense and aspect marking (e.g. simple past, or past progressive). Further, since previous synchronic studies including Broccias (2006a) and Silva (1991) have shown that as-clauses more than while-clauses favour subject

the dot identifies the example as belonging to the fiction register; ' 3 ' identifies the period, i.e. 1700-49 (the first period, 1650-99, corresponds to ' 2 ', i.e. the second half-century counting from 1600), and finally ' $b$ ' specifies that the example is from the British English subcorpus.

7 Our use of 'main clause' is a relative one - it is the superordinate clause on which the simultaneity clause depends. This clause can itself be subordinate to another clause in the sentence. Hence, a more appropriate term would perhaps be 'superordinate' but for the sake of brevity we have used the shorter, albeit less strictly accurate, term 'main clause'.

${ }^{8}$ Halliday identifies six major process types (existential, relational, verbal, mental, behavioural, and material), which are related to three different 'world-types', the world of abstract relations, the physical world and the world of consciousness. The process types are best viewed as forming a continuum rather than well-differentiated categories. 


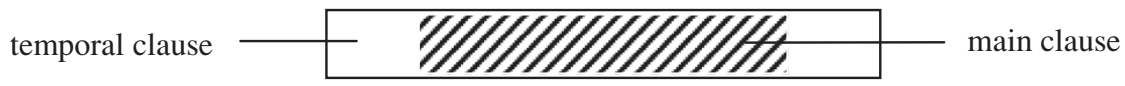

Figure 2. Prototypical simultaneity

identity in the main clause and the temporal clause, as in (4), it seemed appropriate to investigate whether this characteristic obtained diachronically as well. ${ }^{9}$ The last parameter mentioned in table 1, prototypical simultaneity, involves the classification of simultaneity into three major types, namely 'prototypical simultaneity', 'inverted simultaneity' and 'potential simultaneity'. We now explain each type in turn, followed by the notion of 'sequential interpretation', which is also important for our analysis.

Prototypical simultaneity is represented schematically in figure 2. It obtains when the subordinate clause situation (the rectangle in figure 2) 'contains' the main clause situation (represented as the hatching in figure 2 ), ${ }^{10}$ as is the case in (4).

The relation of containment can, albeit rarely (see e.g. section 3.1.2), be reversed so that the main clause depicts a situation containing, rather than contained by, the situation described by the subordinate clause (see also Broccias 2006a on this type and Declerck 1997: ch. 10 and 2006: 637 on 'narrative' when-clauses, which correspond to the type under discussion here). A representative example with as is given in (5), where the event of meeting Rody occurred within the temporally longer situation, depicted by the main clause, of Dick standing at some distance.

(5) ... and as he met Rody, Dick was still standing within about a hundred yards of them ... (1847carl.f5b)

By the term 'potential simultaneity' (which should not be confused with Declerck's 'sloppy simultaneity'; see below) we refer to a type that is similar to what Kortmann (1997: 181-93) identifies as 'simultaneity overlap' and which he exemplifies by way of the sentence When she fell, she caught her. The event of someone's falling overlaps with the event of someone else catching that person, but the two events do not exhibit containment in the sense of figure $2 .{ }^{11}$ This scenario is represented diagrammatically

${ }^{9}$ Subject identity has been operationalized so as to also include cases where the relation between the two subjects is a metonymic one, e.g. the subject of either the main or subordinate clause stands in a part-whole relation with the subject of either the subordinate or main clause. An example is (i), where the pronoun she refers to just one of the entities evoked by the pronoun we in the as-clause.

(i) $\ldots$ and as we went, this young lady told me, she did not well understand me ... (1756amor.f4b)

${ }^{10}$ We would also count as prototypical simultaneity cases where the temporal frame of the main clause can be conceptualized as having roughly the same extension as that of the subordinate clause, as is possibly the case in (i):

(i) We were whispering as we passed down the passage to the infirmary. (1977fras.f8b)

The hatching would spread across the whole rectangle in the visual analogy of figure 2.

11 Kortmann (1997) identifies two other types of simultaneity, namely 'simultaneity duration' (which he refers to as 'while'), as in My parents arrived when I was watching the cup final, and 'simultaneity co-Extensiveness' 


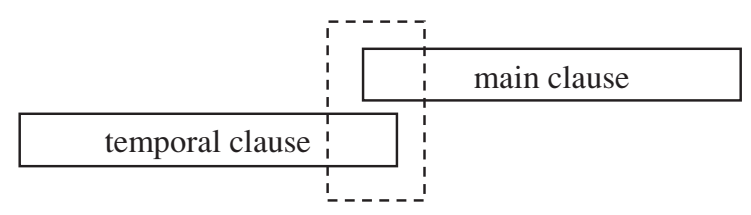

Figure 3. Potential simultaneity

in figure 3, where the subordinate clause situation (the lower rectangle) partly overlaps with the main clause situation (the upper rectangle).

We would like to stress that our notion of 'potential simultaneity' is wider in scope than Kortmann's 'simultaneity overlap'. We use 'potential simultaneity' to refer to cases where it is possible, rather than necessary, to construe some degree of temporal overlap between the main clause and the subordinate clause situations. Example (6) below illustrates this point.

(6) He bowed, however, to the ground as he recognised the ensign of the queen-mother. (1837ains.f5b)

It is difficult, for the reader at least, to decide whether the act of bowing overlapped to some extent with the act of recognising the ensign or immediately followed it (under the latter interpretation, which would probably not be categorized as 'simultaneity overlap' by Kortmann 1997, as is equivalent to as soon as). Such indeterminacy of construal between an overlap interpretation and a sequential interpretation - one event following the other - is precisely what we mean by 'potential simultaneity'.

There thus seems to exist a continuum between prototypical simultaneity and sequential interpretations. For this reason, we have not discarded from our analysis cases where a subordinator is more probably interpreted as sequential rather than simultaneous.

As will be shown in section 3.2.3, the sequential usage is particularly common with when. An illustrative example is (7), where the subordinate event of the Prince's arriving temporally precedes the main clause situation and, thus, when is paraphrasable with 'after'.

(7) When [i.e. after] the Prince came, the Lady and Bileront retir'd to the farther end of the Closet. (1696pix-.f2b)

Thus, the difference between (6), an instance of potential simultaneity, and (7), an instantiation of the sequential interpretation, is the possibility of a sequential interpretation in the former versus the necessity of a sequential interpretation in the latter (although, of course, the classification of other examples may sometimes differ from person to person). Examples like (7) have also been recognized by, for example, Declerck (2006: 648-9) under the rubric of '(pseudo-)sloppy simultaneity', but, for the reasons given above, were not classified as simultaneity examples here.

(which he refers to as 'as long as'), as in When we lived in France, everybody was really friendly to us. In our investigation, both types are subsumed under the label 'prototypical simultaneity'; see also note 10. 
. This section summarizes our findings concerning the subordinator as and, to a lesser extent, while/whilst/when used in past tense contexts, with special reference to the fiction register of the British English component of ARCHER.

\subsection{The subordinator as}

\subsubsection{General trends}

Table 2 provides a breakdown of the distribution of simultaneity as-clauses per register and period. It gives both the number of simultaneity as-clauses found ('raw' for 'raw frequency' in the table) and the corresponding frequency per million words ('pmw' in the table). The last column, which refers to the period as a whole, shows how much each register, in percentage terms, contributes to the overall number of as-clauses. It thus emerges very clearly that as-clauses are most common in fiction, which alone accounts for 63 per cent of all as-examples across the entire period. However, it is important to observe that there is a dramatic increase in the frequency of as-examples in fiction over time. Until the end of the eighteenth century, their frequency (pmw) ranges from 145 to 295, but in the first half of the nineteenth century their frequency peaks at 1,290 , which is roughly a fivefold increase over the immediately preceding period. This peak is followed by a (slight) decrease in the following periods, the lowest dip being that of the latter half of the nineteenth century $(1,086 \mathrm{pmw})$. Still, from the nineteenth century onwards, the normalized frequency is consistently above the 1,000 pmw mark. Before the nineteenth century, fiction is not yet the clearly preferred register for the use of as-clauses since relatively high frequencies, at least in the eighteenth century, can be found in other registers such as science (see in particular the cell for the first half of the eighteenth century in table 4) and journals (especially in the cell for the second half of the nineteenth century). Nevertheless, observe that, first, the raw numbers for science and journals before the nineteenth century are probably too small to warrant any statistically valid conclusions and, second, the relatively similar frequencies for fiction, science and journals over the whole pre-1800 period apparently result from clustering effects or 'burstiness', i.e. the occurrence of most examples in few texts (see Evert 2006). For instance, eight of the thirteen examples for science in the first half of the eighteenth century come from two texts alone (1721lang.s3b and 1722 cay-.s3b contribute four examples each). As for the post-1800 period, it is notable that $a$-clauses seem to have become more common in news writing in the latter half of the twentieth century.

It is instructive to evaluate the spread of simultaneity as-clauses in fiction against their other, non-simultaneity, uses. Such uses include, for example, correlatives or comparatives (8a), parentheticals (8b) and causal instances (8c).

(8) (a) ... till she found his love was as reall [sic] and honest, as it appeared violent ... (1664bult.f2b)

(b) But as I told you, having heard myself mentioned, it raised a curiosity in me to hearken to them. (1702anon.f3b) 


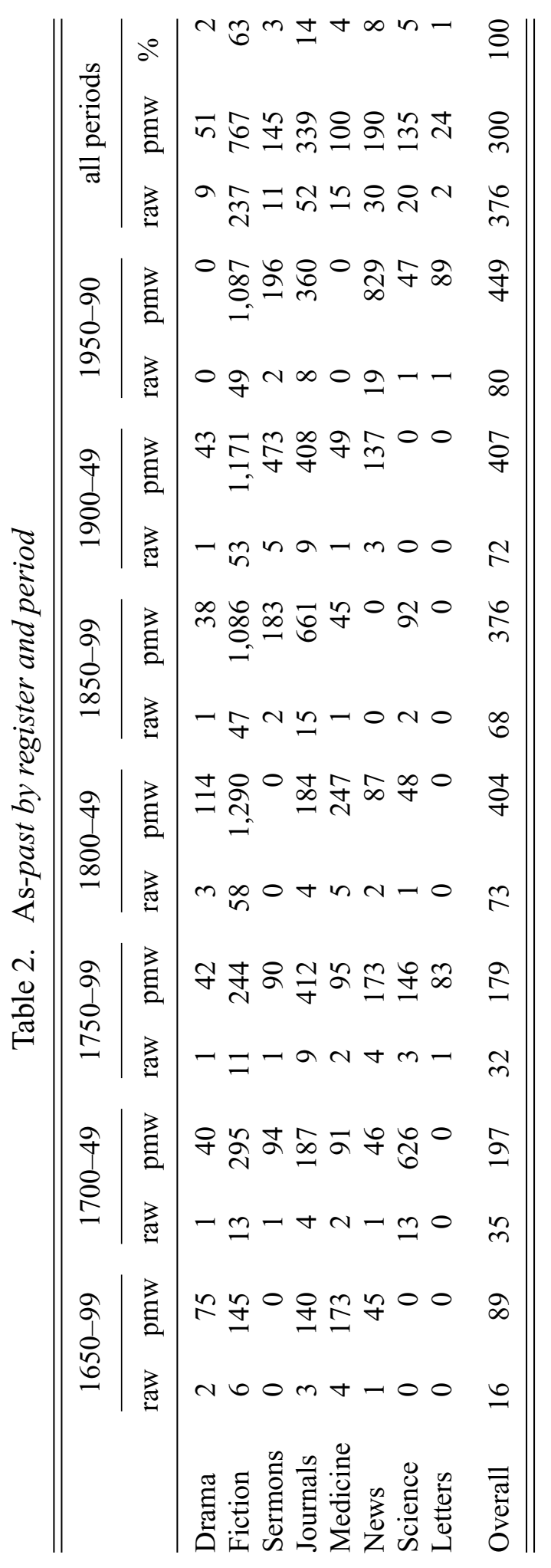


Table 3. The distribution of non-simultaneity as-clauses in fiction

\begin{tabular}{lcrc}
\hline \hline Period & $\begin{array}{l}\text { Raw frequency } \\
\text { soon, just, long })\end{array}$ & pmw & $\begin{array}{l}\text { Non-simul/ } \\
\text { simul ratio }\end{array}$ \\
\hline $1650-99$ & $60(6,0,2)$ & 1,445 & 10.0 \\
$1700-49$ & $93(12,2,0)$ & 2,240 & 7.2 \\
$1750-99$ & $87(12,0,0)$ & 2,096 & 7.9 \\
$1800-49$ & $67(4,3,3)$ & 1,614 & 1.2 \\
$1850-99$ & $40(3,1,1)$ & 964 & 0.9 \\
$1900-49$ & $26(0,1,1)$ & 626 & 0.5 \\
$1950-90$ & $44(3,1,1)$ & 1,060 & 0.9 \\
Overall & $417(40,8,8)$ & 1,435 & 1.8 \\
\hline \hline
\end{tabular}

(c) As I had no friend to whom I could so well commit the care of this infant as herself, I let her take her own way ... (1702anon.f3b)

There are, however, some temporal uses which we have ignored in our survey. Consider the examples in (9):

(9) (a) ... she gladly gave him all her attention as long as attention was possible ... (1818aust.f5b)

(b) As soon as they approach'd him, they venerated and esteem'd him. (1688behn.f2b)

(c) ... and just as they were going to unmoor ship, came a man off shore with a message to the captain ... (1720pitt.f3b)

None of these expressions, which are somewhat idiomatic, conveys prototypical simultaneity to the extent that as on its own can. As long as, for example, can be paraphrased as 'until'. The interpretation of as soon as is not one of simultaneity but one of sequentiality (see also section 2). Just as is usually treated differently from simple as; see, for example, Quirk et al. (1985: 1083) and Broccias (2006a), who notes that just as is, for example, much more likely to trigger the use of the progressive. For the sake of simplicity, we will refer to the types instantiated in (8) and (9) as non-simultaneity as uses.

The spread of as-clauses (in fiction) against the background of the non-simultaneity uses has been summarized in table 3. Observe that the raw frequency column also gives, in parentheses, the number of as soon as, just as and as long as tokens, in that order. Table 3 shows that, in general, non-simultaneity as cases have been declining both in terms of frequency pmw and in relation to simultaneity as cases, as the ratio column on the right shows. This is a very important point: simultaneity as-clauses have not simply increased in frequency in their own right across the last three and a half centuries, but have also done so at the expense of the other uses as-clauses can be put to. Further, our finding (detailed in the next subsection) that over the same period the other major simultaneity subordinators while and when have remained relatively constant in frequency terms (whilst being negligible) underlines the fact that simultaneity as 
has increased not simply in absolute terms, but also proportionally within its field of competition. We return to this issue later, in section 4, where we try to account for the trends observed. First, though, we analyse as-past examples in more detail, using the parameters introduced in section 2, and focusing on fiction.

\subsubsection{Parameters}

Contrary to the change observed in terms of frequency, the behaviour of as in fiction vis-à-vis the parameters detailed in section 2 turns out to be relatively constant and similar to PDE. Since this is also the case with the other subordinators examined here, we will refrain, mainly for reasons of space, from offering detailed statistics, and instead concentrate on the major underlying tendencies.

All three simultaneity types (prototypical simultaneity, inverted simultaneity, potential simultaneity) are discernable with as. The bulk of examples instantiate prototypical simultaneity. Of all 376 as-examples (i.e. across all registers and periods), 350 exhibit this construal and out of 237 fiction examples, 220 of them are of this type. (This also shows, incidentally, that the majority of non- 'prototypical simultaneity' examples, 17 out of 26, are to be found in fiction.) Only four examples of inverted simultaneity (three in fiction and one in news) have been detected in ARCHER. Finally, a few examples instantiate 'potential simultaneity': we identified 22 in our as data, 13 of which occur in fiction. Since the figures for non-prototypical uses are very low, we have not specified the simultaneity types in table 2, where the majority (per period) are of the 'prototypical simultaneity' type.

As for tense and aspect, no changes can be observed. The simple past is the preferred option in both past as and main clauses. The progressive is used rarely in both as and main clauses. Only 15 progressive examples from 1650 to 1990 occur in ARCHER fiction. Similarly, only 7 progressive main clauses, corresponding to 3 per cent of all cases, have been found.

The 'clause order' parameter also points to stability. As-clauses overall occur more often after than before main clauses ( $60 \mathrm{vs} 35$ per cent $)^{12}$. In this case too, the trend is rather stable and on average corresponds to analyses of PDE which make use of larger data sets. For example, Broccias (2008) gives 60 per cent for the post-position option and about 30 per cent for the pre-position option in PDE fiction.

Next we consider the degree to which main and as-clauses can be construed as depicting relatively punctual vs extended (or durative) situations. The most likely scenario ( 55 per cent of all cases on average across all periods) involves both a durative

12 The remaining 5 per cent includes cases either where it was difficult to determine, because of punctuation, the position of the $a s$-clause, or where an as-clause was inserted within the main clause, as in (i) and (ii) respectively:

(i) Beefy with a great grunt and heave lifted her and their hands parted to drop her back down again into the arms of Balthazar. As Beefy lowered himself into Trinity and grinned through the fence bars. 'Come now.' (1968donl.f8b)

(ii) The latter as he went out gazed at him with a good deal of surprise. (1847carl.f5b) 
main clause and a durative as-clause. Another common option ( 30 per cent of all cases) obtains when the main clause depicts a punctual event vis-à-vis an extended $a s$-event. Both cases are clearly examples of what we call 'prototypical simultaneity' (and thus justify this label since, in combination, they account for 85 per cent of all examples). The pattern where both main clause and as-clause are (relatively) punctual is also found, although rarely (11 per cent of all cases); see, for example, (6) above. Finally, the pattern where the $a s$-clause portrays a punctual situation contained within an extended main clause is very rare. We have come across only eight instances (corresponding to 3 per cent of all cases), which we have termed 'inversions', see example (5) in section 2. Once again, we observed that the preferences for the four patterns seem to be relatively stable diachronically.

Previous investigations (see e.g. Broccias 2006a, 2008; Övergaard 1987) have shown that as-clauses in PDE favour change (of place/state) verbs. Broccias (2008), for example, gives 72 per cent as the percentage of change verbs found in past $a s$-clauses in the imaginative written subcorpus of the BNC. Underlining this tendency, we find that 67 per cent of the verbs in the 1950-90 period of ARCHER (i.e. the closest comparable period to the BNC) are verbs of change. The preference for change verbs is undisputable throughout the period examined here since the proportion never drops below 50 per cent in each subperiod and, importantly, no other single class accounts for such large chunks of data. For example, stative examples with be are virtually absent (we counted only two examples), ${ }^{13}$ and verbs of posture and verbs such as wait (which also evoke rather stative situations) are much less frequent (21 examples or 9 per cent in total) than change verbs.

The last parameter investigated has to do with whether the subject of the main clause and the subject of the as-clause are identical (see section 2 and fn. 9 in particular). The data from ARCHER suggests that subject identity is favoured in as-clauses across time (averaging 59 per cent), although a dip from 60 to 49 per cent can be observed from the first to the second half of the nineteenth century. Still, as will be pointed out below (see section 3.2.1), even a figure of about 50 per cent can be interpreted as a preference for subject identity (rather than free variation) if it is compared to sentences introduced by other subordinators, e.g. while-clauses, which overwhelmingly prefer a different subject to that of the main clause.

\subsubsection{Conclusion on as}

The most important finding concerning the development of as-clauses over the last three and a half centuries, in the specific case of fiction, is the rather steep increase in their frequency from the nineteenth century onwards. Compared to the earlier 1650-1799 period, the later data from ARCHER point to a fivefold increase. We have also observed,

13 The 'stative' be examples we found referred, in reality, to impending motion, see (i) and actual motion, see (ii), rather than 'pure' states, see also Broccias (2006a) on PDE.

(i) Stay a minute, 'said he, as she was on the point of departure... (1847gask.f5b)

(ii) It was by a gate in Antiger Lane, as they were on their way, ... (1925powy.f7b) 
however, that the frequency of non-simultaneity as-cases as well as (necessarily) their ratio to simultaneity as-examples declines over time. This means that simultaneity asclauses not only increased in frequency from the nineteenth century but also that they have been eroding, at least in fiction, the other, non-simultaneity, uses. By contrast, when we look more closely at a range of parameters relevant to simultaneity, we find that the overall picture is one of relative stability and consistent with the behaviour of as in PDE. The progressive is rare in both as and main clauses; as-clauses are usually placed after, not before, main clauses; as-clauses overwhelmingly tend to portray situations which subsume or at least co-extend with the situations of main clauses (i.e. 'prototypical simultaneity'); as-clauses are usually found with change verbs; and, finally, subject identity between an as-clause and a main clause is the norm.

\subsection{The other subordinators}

\subsubsection{While}

As was the case with as-clauses, the most representative register for simultaneity whileclauses is fiction; see table 4 . The other registers are too underrepresented to warrant any firm conclusions. But even in the case of fiction, the number of tokens per period (raw frequencies) is unfortunately not high. In general, it seems that the percentage of while-clauses has changed little over the last three and a half centuries. ${ }^{14}$ Moreover, this also seems to be the case if we consider the distribution of simultaneity while-clauses with respect to non-simultaneity while-clauses; see table 5 (which should be contrasted with table 3 for as-clauses).

Because of both the low number of tokens per period and potential clustering effects, our comments regarding the distribution of while across parameters are necessarily limited to a few, fairly clear general tendencies but will draw comparison, where appropriate, with the findings made above on as.

All occurrences in fiction instantiate the 'prototypical simultaneity' type. In other words, the inverted simultaneity and potential simultaneity types that are sometimes found with as are not evidenced with while. Regarding tense and aspect, past simple forms are consistently more common than complex forms in both while and main clauses ( 82 per cent and 80 per cent on average, respectively). Contrary to as-clauses, however, progressive while-clauses seem to be used more frequently (19 per cent on average across all periods) than progressive $a s$-clauses ( 6 per cent on average across all periods). This may be because, as in PDE (see Broccias 2008), the progressive tends to be used more frequently as a marker of susceptibility to change in while-clauses than in as-clauses, where it tends to function as an imperfectivity marker. However, in terms of positioning, while-clauses resemble as-clauses in favouring a post-main clause position in general, on average 61 per cent of the time.

14 The two peaks in the 1700-49 and 1900-49 periods can be accounted for as 'burstiness' effects: 7 of the 16 tokens for 1700-49 come from one text (1723blac.f3b) and likewise 11 examples out of 27 for 1900-49 (1925garn.f7b). 


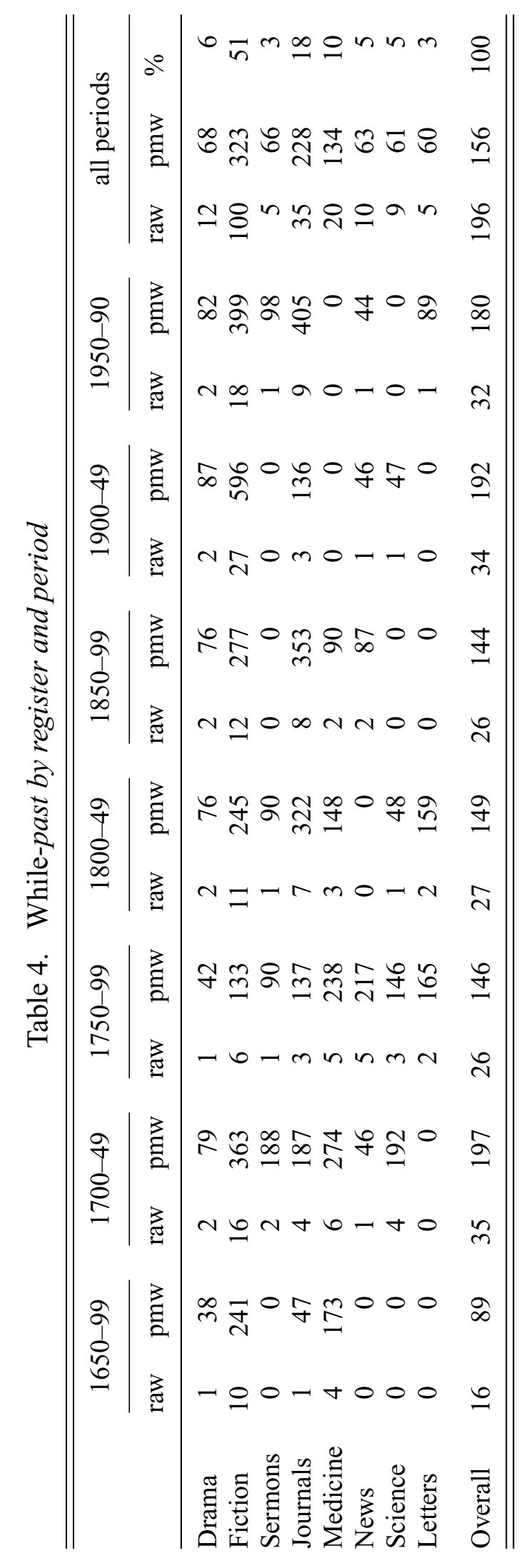


Table 5. The distribution of non-temporal while-clauses in fiction

\begin{tabular}{lccl}
\hline \hline Period & $\begin{array}{l}\text { Raw } \\
\text { frequency }\end{array}$ & pmw & $\begin{array}{l}\text { Non-simul/ } \\
\text { simul ratio }\end{array}$ \\
\hline $1650-99$ & 2 & 48 & 0.2 \\
$1700-49$ & 4 & 96 & 0.3 \\
$1750-99$ & 3 & 72 & 0.5 \\
$1800-49$ & 5 & 120 & 0.5 \\
$1850-99$ & 4 & 96 & 0.3 \\
$1900-49$ & 1 & 24 & 0.0 \\
$1950-90$ & 0 & 0 & 0.0 \\
Overall & 19 & 65 & 0.2 \\
\hline \hline
\end{tabular}

While-clauses in fiction consistently portray relatively durative events. Punctual while-clauses, either in combination with a durative main clause or a punctual main clause, are very rare ( 4 per cent on average). Further, as was observed for as-clauses, the preferred pattern involves both a durative while-clause and a durative main clause (64 per cent on average).

An important difference with respect to $a s$ is the fact that change verbs are never as common with while-clauses as with as-clauses throughout the period. This testifies to the relatively stable temporal nature of while-clauses as opposed to the dynamic nature of as-clauses (see section 1). With the proviso that while-figures should be approached carefully, the highest proportion we have for change verbs used in while-clauses is 36 per cent (in the 1800-49 period) while the lowest proportion for as-clauses is 50 per cent (in the 1650-99 period). The respective averages are 21 and 60 per cent. All in all, it seems that the preference for change verbs is specific to as-clauses throughout the period.

Finally, while-clauses consistently exhibit a stronger preference for different subjects (74 per cent on average) than as-clauses, where the two options are distributed more evenly. As was pointed out above (see section 3.1.2), this can be interpreted as a preference for subject identity in as-clauses vis-à-vis the behaviour of while-clauses.

In sum, while-clauses differ from as-clauses in having generally stable frequencies and in showing a different behaviour with respect to some of the parameters examined. These differences probably derive from the higher compatibility of as with situations that are susceptible to change (see Broccias 2008). What these subordinators do have in common is somewhat stable parametric variability across the period of investigation.

\subsubsection{The subordinator whilst}

The number of simultaneity whilst-clauses in ARCHER is even less than that of simultaneity while-clauses, totalling a meagre 31 tokens across all registers, across the whole period. If we group the data into centuries rather than half-centuries (with the obvious exception of the latter half of the twentieth century; see table 6) so as to 
Table 6. Simultaneity whilst-clauses (of all types)

\begin{tabular}{lll}
\hline \hline Period & Raw frequency & pmw frequency \\
\hline $1650-1749$ & 13 & 36 \\
$1750-1849$ & 10 & 28 \\
$1850-1949$ & 7 & 20 \\
$1950-90$ & 1 & 6 \\
Overall & 31 & 25 \\
\hline \hline
\end{tabular}

ensure a non-negligible amount of data in each period, it is clear that whilst, which was never very common, has declined almost into non-existence. As was the case with simultaneity as and while-clauses, most tokens come from fiction, but the dearth of data makes a parameter-based analysis inappropriate.

\subsubsection{The subordinator when}

The last simultaneity subordinator that we have analysed is when, which is relatively common; see Declerck (1997) for a comprehensive synchronic, non-corpus based, analysis.

In ARCHER, frequencies pmw in fiction over the whole period (see table 7) show that when (past) is intermediate between simultaneity while and simultaneity as (fiction while has a pmw frequency of 323, when 498 and as 767). If, however, we consider all registers together, when (348 pmw) outstrips both while (156 pmw) and as (300 pmw).

Analysing when-clauses in more detail, we find that - just as with as and whileclauses - their overall diachronic behaviour within the domain of fiction is rather constant. Across all periods, the prototypical use (see figure 2 in section 2) is the most common subtype of simultaneity when (91 of the 154 examples in fiction). However, 154 when-clauses in fiction instantiate the 'sequential' interpretation of when in the sense that the when-clause depicts an event which temporally precedes the main clause situation (see (7) in section 2). In terms of frequency, therefore, the use of sequential when-clauses (154 cases in fiction) is even more important than 'prototypical simultaneity' when (91 cases in fiction).

As with the other subordinators, the use of the progressive is marginal with when. When-clauses with the progressive account for only 5 per cent of fiction cases overall, and in this respect when is closer to as (6 per cent) than while (19 per cent).

As for positioning, post-position is favoured across all periods, which is a feature common to the other subordinators as well (see also Diessel 2008 on the positioning of when-clauses).

Considering durativity, we find that the combination of a durative when-clause with a durative main clause is the favoured option (46 per cent on average).

Like while, but unlike as, when combines with a variety of different verb types. In particular, both be and change verbs are relatively common, each category fairly 


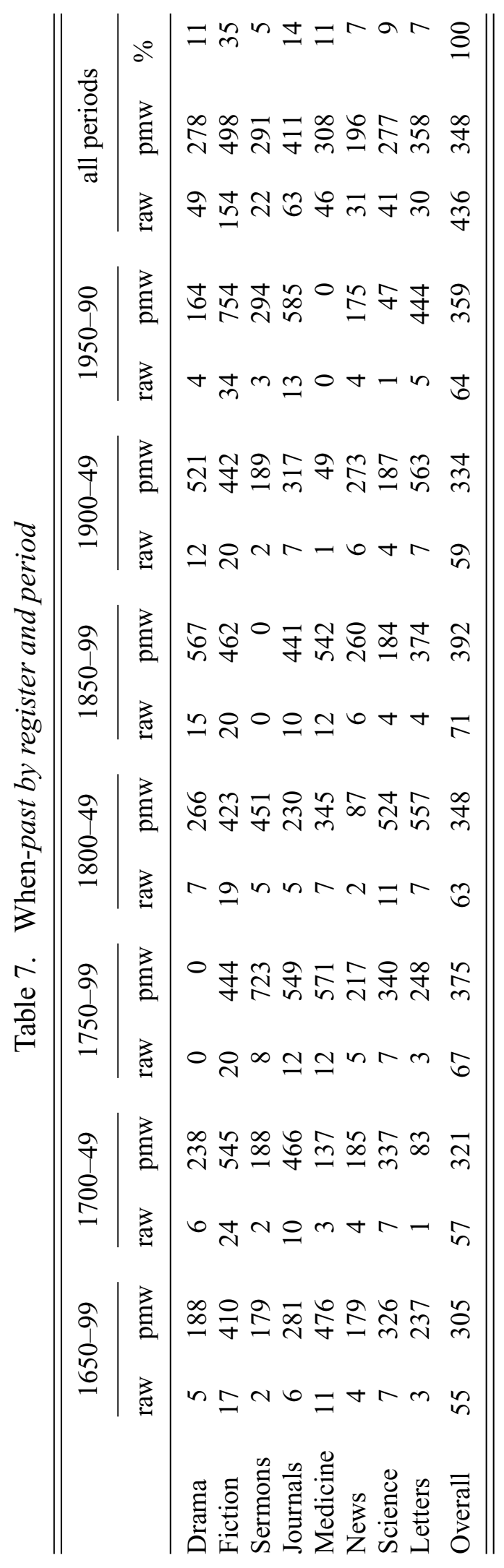


consistently accounting for around 30 per cent of all when cases through time. Importantly, the percentage of be tokens is even higher than with while (which averaged 37 per cent). This may account for the intuition that when is often used as a framing device to refer to a relatively extended and stable temporal frame, as in When he was seventeen ... he told his father that he must go to London (1886giss.f6b). (Notice that examples such as this are difficult with as.) Finally, when behaves similarly to while in that both favour different subjects almost throughout their history (57 per cent on average). Again, this represents a consistent difference with the behaviour of simultaneity as.

\section{Discussion}

Given that simultaneity clauses in general and as-clauses in particular have seldom been the focus of research, it comes as no surprise that there are no systematic references to them in diachronic stylistic analyses. Furthermore, to date, there have been very few quantitative (as opposed to qualitative) investigations into stylistic changes in prose fiction in LModE (see e.g. Fludernik 1996, Adamson 1998 and 1999 for a qualitative approach). The work of Biber \& Finegan (1989 and 1997, in particular) stands out as an exception. They study the development of various registers over the LModE/PDE period using grammatical and functional features grouped into five dimensions, which are interpreted functionally, namely (see e.g. Biber \& Finegan 1997) 'informational vs involved production' (Dimension 1), 'narrative vs non-narrative discourse' (Dimension 2), 'situation-dependent vs. elaborated reference' (Dimension 3), 'overt expression of argumentation' (Dimension 4) and 'non-impersonal vs impersonal style' (Dimension 5). (This last was glossed as 'abstract vs nonabstract style' in their 1989 paper.) They claim, analysing data from ARCHER in terms of Dimensions 1, 3 and 5, that popular registers such as letters, diaries, fiction and news reportage exhibit a drift towards orality, i.e. towards involved production, situation-dependent reference and non-abstract style, starting from the nineteenth century. This shift is claimed to reflect (a) a shift in aesthetic preferences, towards plainer, more colloquial styles, and (b) the spread of mass literacy in the United States and England, which brought about a need to make texts accessible and appealing to a wider audience (1989: 515). By contrast, informational registers, such as science, medicine and legal prose, are said to have become more specialized designed for a 'progressively narrower audience and requiring extensive specialist background knowledge for comprehension' (1997: 269) - and more literate. That is, informational registers have shown a trend towards a less, rather than more, speech-like style. These opposing tendencies, Biber \& Finegan argue, have resulted in a widening divergence of prose styles in the last three and a half centuries.

Analogously, our findings indicate that across the same period, the distribution of the simultaneity subordinators has been in a state of flux. Temporal as-clauses have expanded since the early nineteenth century and have been eroding other nonsimultaneity as-uses. Whilst-clauses have been rapidly falling out of use. On the other hand, the behaviour of while and when-clauses seems to be rather constant. 
Also (relatively) constant are the general preference for postpositioning with all the subordinators (which, as mentioned above, is consistent with Diessel 2008, although he does not distinguish between spoken and written language), the preference for different subjects in while and when-clauses as opposed to as-clauses, the preference for 'prototypical simultaneity' and the paucity of progressive forms especially in asclauses (when and while fare better in this respect - see Broccias 2008 for an explanation of the difference between progressive while and progressive as). ${ }^{15}$

All in all, our data are thus partially consistent with Biber and Finegan's conclusion that important changes can be observed from the first half of the nineteenth century. It is certainly so in the case of as-clauses and whilst-clauses (and see also fn. 15 on bare participles). $A s$-clauses were consistently much less frequent in the 1650-1799 period so that their expansion in the nineteenth century is a major development.

The obvious question is: can we take the spread of as-clauses and the demise of whilst-clauses as evidence of the drift towards orality in fiction observed by Biber and Finegan? The decline of whilst-clauses can undoubtedly be seen as a result of a drift towards a more oral style because whilst is regarded nowadays as a formal subordinator. (The formal nature of whilst is specified in dictionaries such as the Longman Dictionary of Contemporary English, for example.) But what about asclauses? It is unclear where to place $a s$-clauses (as well as the other subordinatorintroduced simultaneity clauses in general) in Biber and Finegan's classificatory system since they are not explicitly mentioned. Two potential features under which they could be subsumed are 'time adverbials' (included under Dimension 3 as contributing to situation-dependent reference and, hence, orality) and 'other adverbial subordinators' (included under Dimension 5 as contributing to an abstract style and, hence, a nonoral style). ${ }^{16}$ Let's begin with the latter. Biber and Finegan claim that the features clustering into Dimension 5 are 'used to present propositions with reduced emphasis on the agent, giving prominence to the patient ... This promoted entity is typically an inanimate referent and is often an abstract rather than a concrete entity' (1989: 492). This characterization applies mainly to passive constructions and it is therefore difficult to see how it could be relevant to as-clauses, which, incidentally, usually contain animate subjects. ${ }^{17}$ Alternatively, as-clauses could be seen as instances of 'time adverbials' (under Dimension 3). But it is not clear what exactly this label subsumes. Still, it is

15 As part of our ongoing research into simultaneity from 1650 onwards, we additionally investigated simultaneity bare participles (e.g. 'No, no, 'said he, laughing [1839mart.f5b]). Early indications based on a random sampling of retrieved cases suggest that (a) these constructions are very common, in fact, more common than each of the subordinators individually; (b) after a decline in the eighteenth century, they have apparently increased in overall frequency; (c) they are increasingly carving out constructional niches (e.g. they are frequently found after the main clause in general and following verbs of saying in particular). Clearly it will be useful to investigate these constructions further, and the impact they have on as.

16 Biber and Finegan include 'subordination' also under Dimension 1 but restrict it to 'causative subordination', which they regard as contributing to 'involved production' and, hence, an oral style. Causal as-clauses would therefore be included there.

17 Just sampling, when possible, the first ten fiction examples per subperiod (remember that there are only six fiction examples in the 1650-99 subperiod), we find 100 per cent of subjects are animate for all subperiods with the exception of 1850-99, where one example contains an inanimate subject. 
undeniable that as-clauses provide information about 'the actual physical context of discourse' (1989: 492) since they orientate events with respect to each other in terms of temporal containment or overlap. Recall also that as-clauses often make use of motion verbs - a subclass of change verbs - and that spatiality in general is taken by Biber and Finegan to be a marker of situation-dependent style. ${ }^{18}$ Further, temporal subordinators are usually treated differently from 'logical' ones in that the latter are on the whole viewed, e.g. by Adamson $(1998,1999)$, as symptomatic of a more elaborated style. (But note that Biber and Finegan class causative (sc. causal) subordination, manifestly an instance of logical subordination, as an example of involved rather than informational production; see fn. 16.)

This line of reasoning would lead us to conclude that the growth of as-clauses also supports Biber and Finegan's finding of a transition towards more oral styles. The fact that as-clauses often contain change events may motivate why they, rather than the other subordinators, have increased the most. By being temporal adverbials and by often containing reference to spatiality (e.g. motion along a path) as do place adverbials, they have a privileged status as markers of situation-dependent reference.

In order to substantiate this conclusion, we would need studies which analyse how simultaneity is expressed in oral language. Luckily, there is just one study that addresses this issue, namely Silva (1991). Silva compares the production of simultaneity clauses in children's and adults' narratives and finds that children (even up to ten years of age) use simultaneity markers as, while and when differently from adults in narrative discourse. Her study shows that 'children in all age groups virtually never used as to signal the particular class of simultaneous relations adults mark with this particle, preferring - if they used subordinate strategies at all - when or while in these contexts' (1991: 658). (This finding is also related, incidentally, to Silva's other finding about when usually having a sequential interpretation only in adults' language, which is also what the corpus evidence from ARCHER suggested for written language throughout the period examined.)

Silva justifies the late acquisition of $a$ s as a simultaneity subordinator by claiming that as, like the Turkish simultaneity particle erek studied by Slobin (1988), 'is essentially a narrative form, and its proper use requires an ability to manage attention flow in narrative' (Slobin 1988: 16, cited in Silva 1991: 660). Further, Silva speculates that the increase in the preposing of when she observed as children grow up may also be indicative of children's beginning to master the management of attention flow in narrative. That is, children learn to use when (and as) as narrative 'signposts', which are understandably more common in initial position. The end of this developmental path is the mastery of $a$-clauses for narrative purposes, which Silva finds are also typically preposed.

The last observation is highly significant for the present study. We have found that $a s$-clauses in fiction are typically found in post-position rather than pre-position. Hence,

18 Biber and Finegan take spatial particles (e.g. out, away, down), for example, as evidence of a more situationdependent style (1989: 503). 
just this simple observation casts doubt on viewing the spread of $a$ s-clauses as a trend towards oral style because oral narrative style and written narrative style clearly diverge in this respect.

However, it is worth comparing the increase in as-clauses observed in children as they mature into adulthood with the spread of as-clauses observed in fiction as it matures into 'modern' nineteenth-century narration. That is, if Silva is correct in claiming that the use of simultaneity as-clauses requires greater sophistication, i.e. greater mastery of information flow, then the growth of as-clauses in fiction may be taken to reflect a more 'mature' approach to narration. In particular, the use of as-clauses, as is argued in Silva (1991) and Broccias (2006a), 'requires that the actions specified in the predicates of the two clauses be seen as an essentially unitary event' (Silva 1991: 648). This explains why, for example, subject identity is favoured in as-clauses as opposed to while-clauses: different subjects enhance the potential for a contrastive construal of the main and subordinate clause events; hence, the concessive interpretation often associated with while.

In sum, we contend that the spread of simultaneity as-clauses, as opposed to the other simultaneity subordinators, provides further empirical support for Biber and Finegan's claim about the changing nature of fiction over the LModE period. Nevertheless, we do not interpret such an increase as symptomatic of a trend towards orality. As the data from Silva (1991) show, as-clauses tend, for example, to be preposed in oral narrative, while the opposite is the case in fiction. Rather, we view the increase in simultaneity as-clauses as indicative of an evolution in narrative techniques (in the same way as the spread of as-clauses in oral narrative from childhood to adulthood implies maturation of oral narrative techniques). Narration (in fiction) becomes more 'mature' in that writers are increasingly proficient at 'building global or composite event representations' (Slobin 1988: 16). In other words, the conceptual schema associated with $a s$-clauses (a path event along which another event takes place so that the two are intimately connected; see e.g. Broccias 2006a), becomes progressively more entrenched in the recent history of the English language.

A word of caution is needed, however. It should not be assumed that the use of simultaneity as-clauses is indicative of a 'high' style. As was pointed out above, it is found, for example, in the ordinary, everyday language of adults. ${ }^{19}$ Rather, the increase

19 Similarly, it is commonly found in summaries of television series episodes. The following summary of a single episode of the British soap opera Emmerdale is truly replete with as-clauses (from www.digitalspy.co.uk/soaps/a174426/chas-begs-paddy-for-a-chance-to-explain.html):

Fuming, Paddy reels as he takes in the news that Chas has betrayed him with Carl ...

Desperate, Chas is in tears as she begs him to give her a chance to explain. Paddy, however, is adamant - he's disgusted by her actions and he wants her out. Chas collapses to her knees in a sobbing state as Paddy walks away ...

Cain enters the house as a flustered Debbie wonders how to sneak Michael out. She's frantic as she makes excuses in the hope of convincing Cain to leave. He finally relents, much to Debbie's relief.

However, as Debbie waves goodbye to Michael, she's worried when Ryan spots them and he quickly realises that something's been going on ... 
in simultaneity as-clauses mirrors the emergence of more sophisticated conceptual packaging techniques, by which events are viewed as components of an integrated whole. Such integration manifests itself formally, for example, via the use of identical subjects in the main and as clauses and semantically by virtue of the fact that a path event is often construable as a cause for the main event. Importantly, the 'composite event representation' underlying the use of $a$ s is so useful that it is not restricted to narrative style only but can also be observed in headlinese, where as is probably used because of its semantic flexibility in depicting the existence of some relation (either temporal or causal or both) between two events, as the following examples show:.

(10) (a) Reformed party girl Meg Mathews embarks on health kick as she prepares to wed again (Daily Mail, 11 Aug. 2009)

(b) Shoppers turn to winter foods as washout summer makes us axe the barbecues (Daily Mail, 11 Aug. 2009)

(c) Fixed rate mortgage costs rocket as lenders increase margins to record highs (Daily Mail, 11 Aug. 2009)

(d) Piracy fears as cargo ship disappears off UK coast (The Times, 11 Aug. 2009)

(e) Hundreds feared dead as typhoon hits Asia (The Times, 11 Aug. 2009)

(10a) does not simply code simultaneity between Meg Mathews's getting in shape and the preparations for her wedding, but invites the latter event to be interpreted as a cause of the former one. Similarly, in (10b), as the text of the article explains, 'the nation turns to comfort food as a result of [our emphasis] the washout summer weather'. A causal interpretation is also intended in (10c), alongside the temporal one, and probably predominates in the remaining examples $(10 \mathrm{~d}-\mathrm{e})$.

At a more general level, our conclusions appear to be in accord with new research by Douglas Biber on the emergence of grammar within different genres or registers. Biber (2008) identifies a number of new uses of grammatical constructions, as well as possible new constructions, that - contrary to conventional wisdom on language change have emerged within the domain of academic writing. The communicative demands of this register - for example, the requirement to convey increasingly specialized kinds of information - are claimed to lend themselves to such elaborations in noun phrase structure as the use of abstract nouns as premodifiers, e.g. phase velocity and strength characteristics. Extending this line of argument, Biber suggests that grammar can emerge in any register, 'reflecting the communicative priorities of that register' (Biber 2009, personal communication). The emergence of simultaneity as, along the lines we have described, in fiction (and possibly newspaper headlinese, which should be the object of future investigation) does not involve a new construction per se. However, it does seem to represent a plausible further candidate of register-specific evolution in grammar.

Elsewhere, Ashley's team is losing the cricket match and Vincent has been taunting him throughout. As he starts praying to win, his fast bowl knocks Vincent to the ground and he's taken to hospital ...

Just as Ashley and Laurel are hopeful that it's the last they'll be seeing of Vincent and Sally, Douglas leads them into the house ... 
We would like to conclude by stressing that much remains to be done in the diachronic study of simultaneity constructions. Here we have only addressed the 'recent' history of simultaneity subordinators. Further, we would like to stress that larger corpora are needed both to investigate registers other than fiction in detail and, even in the case of fiction, to corroborate the tendencies observed in the ARCHER corpus. To be sure, our major finding concerning the spread of simultaneity as-constructions in fiction calls for an integrated approach, where quantitative, i.e. corpus-based, and qualitative, e.g. stylistic, analyses are both needed, simultaneously.

Authors' addresses:

Facoltà di Lingue e Letterature Straniere

Università di Genova

Piazza S. Sabina 2

16124 Genova

Italy

c.broccias@unige.it

School of English, Sociology, Politics \& Contemporary History

University of Salford

Manchester M5 4WT

UK

n.smith@salford.ac.uk

\section{References}

Adamson, Sylvia. 1998. Literary language. In Suzanne Romaine (ed.), The Cambridge history of the English language, vol. 4, 589-692. Cambridge: Cambridge University Press.

Adamson, Sylvia. 1999. Literary language. In Roger Lass (ed.), The Cambridge history of the English language, vol. 3, 539-653. Cambridge: Cambridge University Press.

Beal, Joan. 2004. English in modern times. 1700-1945. London: Arnold.

Biber, Douglas, Edward Finegan \& Dwight Atkinson. 1994. ARCHER and its challenges: compiling and exploring A Representative Corpus of Historical English Registers. In Udo Fries, Gunnel Tottie \& Peter Schneider (eds.), 1-14. Creating and using English language corpora. Amsterdam: Rodopi.

Biber, Douglas. 2008. Corpora and the history of English: ARCHER 3 and beyond. Paper presented at the ARCHER symposium, Freiburg, 12 December 2008.

Biber, Douglas \& Edward Finegan. 1989. Drift and the evolution of English style: A history of three genres. Language 65, 487-517.

Biber, Douglas \& Edward Finegan. 1997. Diachronic relations among speech-based and written registers in English. In Terttu Nevalainen \& Leena Kahlas-Tarkka (eds.), To explain the present: Studies in the changing English language in honour of Matti Rissanen, 253-75. Helsinki: Mémoires de la Société Néophilologique de Helsinki.

Biber, Douglas, Stig Johansson, Geoffrey Leech, Susan Conrad \& Edward Finegan. 1999. Longman grammar of spoken and written English. Harlow: Longman.

Broccias, Cristiano. 2006a. The construal of simultaneity in English with special reference to as-clauses. Annual Review of Cognitive Linguistics 4, 97-133.

Broccias, Cristiano. 2006b. The English simultaneity network: The case of as and while-clauses. LACUS Forum 32, 33-41. 
Broccias, Cristiano. 2008. Imperfectivity and transience: The two sides of the progressive aspect in simultaneity clauses. Journal of English Linguistics 36, 155-78.

Christ, Oliver. 1994. A modular and flexible architecture for an integrated corpus query system. Proceedings of COMPLEX' 94. Third Conference on Computational Lexicography and Text Research (Budapest, 7-10 July 1994), 23-32. Budapest.

Declerck, Renaat. 1997. When-clauses and temporal structure. London: Routledge.

Declerck, Renaat (in collaboration with Susan Reed \& Bert Cappelle). 2006. The grammar of the English tense system. Berlin: Mouton de Gruyter.

Diessel, Holger. 2008. Iconicity of sequence. A corpus-based analysis of the positioning of temporal adverbial clauses in English. Cognitive Linguistics 19, 457-82.

Evert, Stefan. 2006. How random is a corpus? The library metaphor. Zeitschrift für Anglistik und Amerikanistik 54, 177-90.

Fludernik, Monika. 1996. Towards a 'natural' narratology. London: Routledge.

Garside, Roger \& Nicholas Smith. 1997. A hybrid grammatical tagger: CLAWS 4. In Roger Garside, Geoffrey Leech \& Anthony McEnery (eds.), Corpus annotation: Linguistic information from computer text corpora, 102-21. Harlow: Addison Wesley Longman.

González-Cruz, Ana I. 2007. On the subjectification of adverbial clause connectives: Semantic and pragmatic considerations on the development of while-clauses. In Ursula Lenker \& Anneli Meurman-Solin (eds.), Connectives in the history of English, 145-66. Amsterdam: John Benjamins.

Halliday, M. A. K. 2004. An introduction to Functional Grammar, 2nd edition. London: Hodder Arnold.

Kortmann, Bernd. 1997. Adverbial subordination: A typology and history of adverbial subordinators based on European languages. Berlin and New York: Mouton de Gruyter.

Morris, Lori. 1996. Time and cause in the English connector as. LACUS Forum 23, 417-28.

Övergaard, Gerd. 1987. Duration, progression, and the progressive form in as-clauses. In Ishrat Lindblad \& Magnus Ljung (eds.), Proceedings from the Third Nordic Conference for English Studies, vol. 1, 265-80. Stockholm: Almqvist \& Wiksell International.

Pasicki, Adam. 1983. While-clauses in Old and Early Middle English. Folia Linguistica Historica 4, 287-303.

Pasicki, Adam. 1987. Temporal adverbials in Old and Middle English. Lublin: Radakcja Wydawnictw Katelickiego Uniwersytetu Lubelskiego.

Quirk, Randolph, Sidney Greenbaum, Geoffrey Leech \& Jan Svartvik. 1995. A comprehensive grammar of the English language. Harlow: Longman.

Schmiedtová, Barbara. 2004. At the same time . . . : The expression of simultaneity in learner varieties. Berlin: Mouton de Gruyter.

Silva, Marilyn. 1991. Simultaneity in children's narratives: The case of when, while and as. Journal of Child Language 18, 641-62.

Slobin, Dan. 1988. The development of clause chaining in Turkish child language. Paper presented at the Fourth Conference on Turkish Linguistics, Middle East Technical University.

Smith, Nicholas. 1997. Improving a tagger. In Roger Garside, Geoffrey Leech \& Anthony McEnery (eds.), Corpus annotation: Linguistic information from computer text corpora, 137-50. Harlow: Addison Wesley Longman. 